\title{
Access to Modern Energy Initiatives by Rural Household in Homa Bay County, Kenya
}

\author{
Odago A. Donata \\ School of Arts and Social Sciences, \\ Deparment of Development Studies \\ Moi University \\ Mulongo S. Leonard \\ School of Arts and Social Sciences, \\ Deparment of Development Studies \\ Moi University \\ Mining Pacifica \\ School of Arts and Social Sciences, \\ Deparment of Development Studies \\ Moi University
}

\begin{abstract}
The failure to provide energy access continues in many parts of the world today. It is estimated that three million people in the world lack access to energy infrastructure and use biomass solid fuels such as charcoal firewood, dung or crop residue for cooking. Apart from being highly inefficient, these traditional, open fire cookstoves produce toxic particulates that cause indoor air pollution and contribute to around four million premature deaths per year especially among women and children. The paper based on a study undertaken in Homa Bay is focused on identifying the energy initiatives in Homa Bay County, and how consumers perceive ICS with respect to traditional stoves. The study used Ex post facto research design using mixed method to collect data which was obtained using data collection instruments such as questionnaires, FGD, Key informant interview schedules and researcher's observation. The study used systematic and cluster sampling to get a representative data. The study was based on the capability approach theory that people ought to be made equal in their capabilities or at least in their basic capabilities. The study found that household cooking technologies came from two main source namely three stone fire and Kenya ceramic jiko. The main sources of household cooking fuel were biomass, kerosene and LPG. Use of open fire and overdependence on solid biomass resulted in respiratory illness and eye discomfort caused by IAP and black carbon. Low adoption of solar and electricity resulted in high use of kerosene tin lamp as source of light. The study concludes that there is a need to strengthen efforts to promote use of ICS, which use biomass in a more efficient way. The promotion and distribution of ICS should be linked with funding for climate-related projects, with the aim of reducing the cost of the stoves and creating added economic incentives to replace old, inefficient cookstove models.
\end{abstract}

Key Words: Energy, Livelihood, Improved cookstove, clean cooking, Biomass

\section{INTRODUCTION}

While 1.3 billion people have no access to electricity, more than double that number, approximately 3 billion people, mainly in South Asia and Sub-Saharan Africa, are still relying on solid fuels for cooking and heating (UNDP and WHO 2009; IEA 2012). Solid fuels in the form 
of traditional biomass (wood, animal dung, crop residues, and charcoal) are used by nearly 2.6 billion people, while solid fuels in the form of coal are used by about 0.5 billion people, mainly in China and to a lesser extent in India and South Africa. In Ethiopia, DR Congo, Tanzania and Uganda biomass accounts for as much as 93 percent to 95 percent of the total energy consumed. A similar pattern holds true in many countries in the region. 2 million people (mainly women and children) die because of the burning of biomass indoors. About 10 million people, mostly rural poor, have gained access to modern energy services through UNDP supported projects over the past decade (UNDP 2011, UNDESA 2010, IEA 2011, WHO 2011). While the use of traditional energy sources is not necessarily undesirable in itself, concerns have been raised over how they are currently being used.

In developing countries, use of traditional biomass stoves for household cooking require extensive local fuel collection and can create additional pressure on local forests and ecological systems. Even though the collection of fuel wood does not directly cause deforestation because the branches are mainly collected from agricultural lands or roadsides the production of charcoal from fuel wood burning has been proved to aggravate land degradation in subSaharan Africa (Arnold et al., 2003; IEA, 2006). Traditional stoves and open fires are inefficient at converting energy into heat for cooking; the amount of biomass cooking fuel required each year can reach up to 2 tons per family; local environmental problems can result where demand for local biomass outstrips the natural regrowth of resources (Ramanathan and Carmichael 2008; Venkataraman et al. 2010). Also, if fuel wood and charcoal resources are not adequately available, the use of animal dung and agricultural residues for fuel would have to increase, resulting in a reduction of soil fertility and direct competition with animals that rely upon crop residue and the shrubs for fodder (Kaale, 1990). While many local communities can and do manage their biomass supplies sustainably, tremendous amounts of time, a burden shouldered disproportionately by women and children, may be spent collecting and managing these resources (Kammen, 2002; Dutta, 2003; Clancy and Skutsch, 2003).

\section{Energy Initiatives}

\section{LITERATURE REVIEW}

\section{The Kenya Ceramic Jiko}

The Kenya Ceramic Jiko (KCJ) is one of the successful stove dissemination projects in Africa. The Kenya Ceramic Jiko was created after re-designing the Thai Bucket Stove and the Kenya Traditional Metal Stove (KENGO, 1991; Karekezi and Kithyoma, 2002, Coelho et. al 2004). Organizations such as CARE, UNICEF, The Bellerive Foundation, as well as the United Stated and German aid agencies all played a role in the development and promotion of the KCJ. The Kenya Energy and Environment Organization (KENGO) has played an active role in increasing awareness, and promoting the use of the Kenya Ceramic Jiko since 1982 (KENGO, 1991, Kammen, 1995).

A study carried out by Co2 balance in partnership with the Global Alliances for Clean Cookstove and fuels revealed approximately $89 \%$ of rural and $7 \%$ of urban households regularly use firewood, giving a national average of about $70 \%$ of all households. Overall, about $21 \%$ of households use farm residues, but their use is mainly in rural areas with $29 \%$ households as compared to $0.5 \%$ in urban households. Only $2.5 \%$ of households use wood waste (sawdust, bark and small off-cuts). Use is mainly in urban areas by $3.7 \%$ of households as compared to $2.1 \%$ in the rural areas. Use of charcoal is about $47 \%$ at the national level with use of over $82 \%$ and $34 \%$ of urban and rural households, respectively. Per capita consumption is $156 \mathrm{~kg}$ in urban areas and $152 \mathrm{~kg}$ in rural areas (SCODE, 2012).This has implication for sources of biomass since cutting down trees for fuel has led to environmental degradation, including loss of forests, loss of biodiversity, destruction of habitats, and an increase in soil 
erosion. It also means that many people in the rural households especially women and children are exposed to indoor air pollution which is detrimental to their health thus the need for adoption of the improved stoves.

When used properly, the Kenya Ceramic Jiko has the ability to reduce fuel consumption by 20$50 \%$ (Smith et al., 1993), therefore reducing the demand for wood as a fuel resource. The stove may reduce $20 \%$ of emissions produced from incomplete combustion (Johnson et al., 2007). In addition, the Ceramic Jiko increases child safety as the ceramic liner prevents the stove from becoming extremely hot. Although most producers and dealers of the jiko stove have been men, many women in small urban areas have benefited immensely from the technology, significantly improving their standards of living through gains in time and income (Okello, 2005).

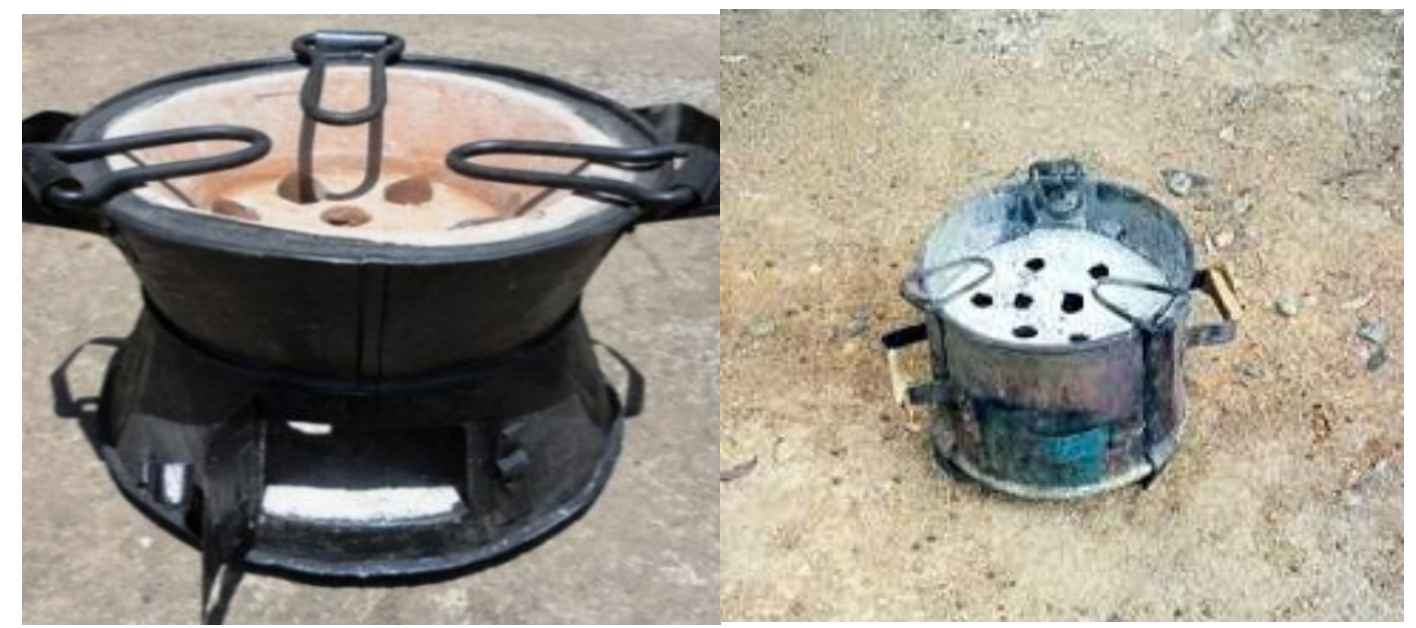

IMAGE 1:The Kenya ceramic jiko

IMAGE 2: The Kenya traditional metal stove

\section{SCODE Energy Saving Cookstove}

SCODE (Sustainable Community Development services) social is a community based organization started in the year 1996 with the aim of enabling people in Kenya especially the poor, to improve their quality of life by adopting technologies and approaches that are environmental friendly and contribute towards sustainable development. SCODE's mission is to facilitate adoption of cleaner energy technology and sustainable land use approaches through capacity building and applied research for enhanced livelihoods with concern for the environment and sustainable development.

SCODE enterprise promotes a wide range of energy saving cookstoves (jikos) that are designed to reduce on fuel-wood consumption when used properly .The stoves are made from long lasting materials, high quality workmanship and are well insulated to minimize heat losses and come with a 6-12 months guarantee. Because of these qualities, there is reduced drudgery that women go through when fetching firewood, women cook more with less fuel-wood and time, reduce smoke emissions in the kitchen compared to the traditional three stone fireplace, the stoves last longer and reduce fire accidents among men and women in kitchens. 


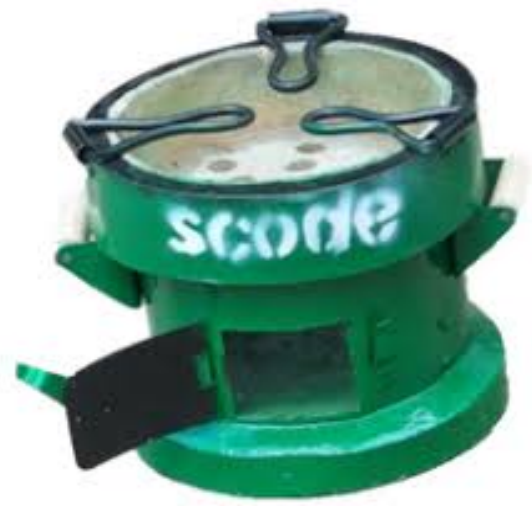

IMAGE 3: Jiko Star

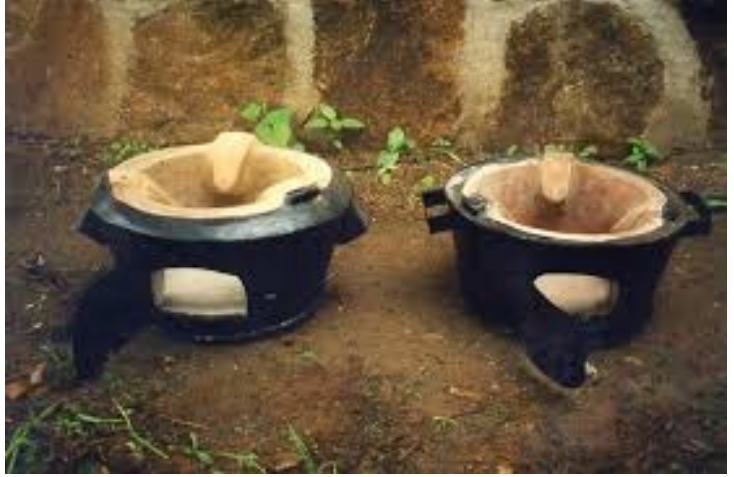

IMAGE 4: Kunimbili jiko

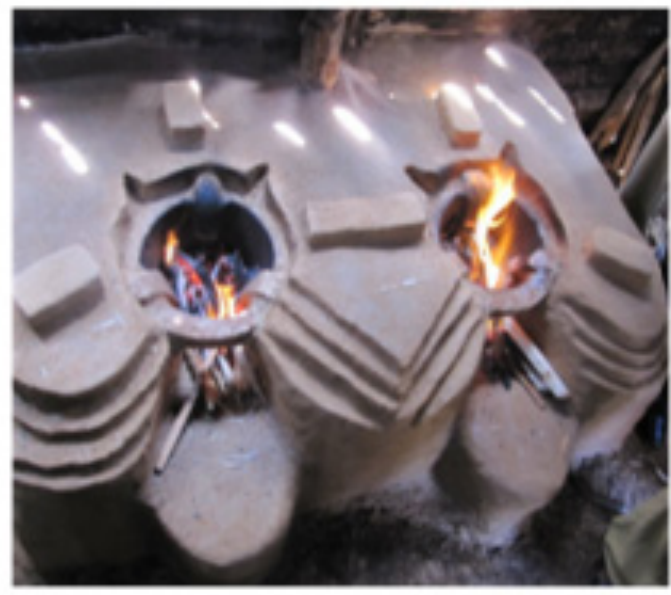

IMAGE 5: Jiko Kisasa

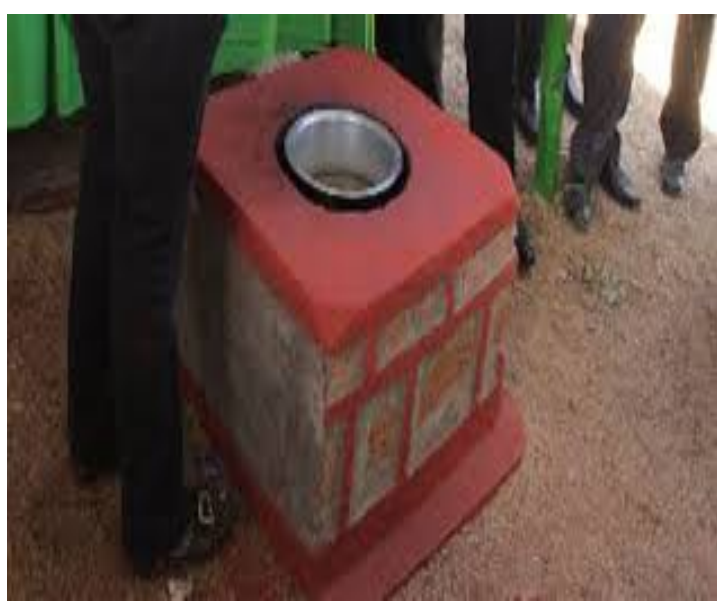

IMAGE 6: Rocket Stove

Jiko Star is a charcoal-burning stove specially designed to reduce charcoal consumption, carbon monoxide emission and last longer. Kunimbili is a highly efficient wood stove which can also use charcoal. It's specially designed to reduce charcoal consumption, carbon monoxide emission and last longer. SCODE jikokisasa stove is a portable pottery cylinder (ceramic liner) that is installed by building a mud or concrete surrounding in the kitchen. It is suitable for use in households and institutions with a permanent fireplace. A Rocket stove is a firewood burning stove. There are three types: Mud, mud-brick and cement brick rockets. It cooks faster, fairly affordable and environmentally friendly. The sizes vary with each household and/or institution.

For SCODE the programmes have seen over 70,000 people in their respective areas become aware of the ICS and its benefits and install more than 25,000 jikos in their households. Consequently, these households have reported savings of between 40 and 50 percent on firewood use.

\section{LPG Consumption in Kenya}

The global focus on LPG is largely underpinned by the fact that LPG is the most efficient source of energy after electricity. Kenya signed the KYOTO protocol of 2010, which among other areas sought to promote modern energy usage to reduce pollution and more importantly, save the environment and promote health benefits. The use of biomass as the main energy in the Kenyan economy especially in the rural setting is over $80 \%$ on average. This unsustainable practice is a major health risk to the population. According to the report published by PIEA in the third quarter of 2016, the annual LPG consumption in Kenya stood at 148,800 MT. The 
reports available in the Petroleum Industry subsector in Kenya Even show that LPG consumption has increased by about 59\% between 2003 and 2016 .

Despite this rapid growth, LPG Consumption in Kenya still compares poorly with world statistics at 95.5Ktoe against a world average of 1434Ktoe and 384Ktoe in low income economies (Ministry of energy report-MOE). Kenya's LPG per-capita consumption lags behind countries in Africa at $3.65 \mathrm{Kg}$ in rural and 9.87 in urban areas compared to Senegal which is at $75 \mathrm{Kg}$ according to MOE reports. This consumption has however been rising at a steady pace. At an average growth of $14 \%$ annually (PIEA 2016) it is projected that the country will have $70 \%$ LPG penetration by the year 2030. However, this growth has mainly been concentrated in urban and peri-urban areas of Kenya. Even with an annual growth of $14 \%$ of LPG consumption, a lot more needs to be done to catch up with the rest of the world in promoting LPG.

The low LPG consumption prompted the government of Kenya to make an announcement to start an LPG subsidy program that targeted the low-income population especially in rural Kenya in October 2016. The total subsidy was reported to be upwards of $50 \%$ of cost on both accessories and the gas. In Kenya, and especially to the majority of the rural households living on less than a dollar a day, the initial cost of cylinder and accessories at an average of 400 dollars is unaffordable. It is not only expensive for the people at the bottom of the pyramid; it is unreachable competing with food and shelter at that basic level. The gap is widening and households would rather choose food over efficient fuel. This is the gap that the government perhaps hopes to bridge to aid in the upfront purchase of the cylinder, gas and accessories, through subsidy. Since it is estimated that over 97 percent of Kenya's nine million households rely on traditional sources of cooking energy (Dalberg, 2013), and that many households practice energy stacking, supplementing modern energy such as LPG with alternative sources of fuel such as wood, charcoal and kerosene. A deliberate effort has to be made to guide a household's hands to choose more efficient, more economical energy sources, LPG therefore should be at the forefront of this energy ladder.

\section{The Kenya National Biogas Initiative}

Kenya began to Plan for the implementation of a national domestic biogas programme on 23rd May 2007, when a number of stakeholders met and founded the Kenya Biogas Task Force. The spirit of this Kenyan initiative resulted from the May 2007 Biogas for Better Life Conference (KBFS, 2007; SNV, 2009). This was followed by a meeting of representatives from 27 countries in Africa in Nairobi to formally discuss how to carry forward the objectives of an Africa-wide biogas initiative with the support of the Directorate General for International Cooperation (DGIS) under the Netherlands Ministry of Foreign Affairs (SNV, 2009). The Kenya Biogas Task Force reconstituted into the current broad based Kenya National Biogas Initiative Committee (KENBIC), chaired by Kenya's Ministry of Energy (MoE) on 25th June 2008. Its main objective is realisation of a national biogas programme for Kenya (ABPP, 2008).

In the context of Biogas for Better Life, the Shell Foundation commissioned and funded a feasibility study in 2007 to examine the potential for a national domestic biogas programme in Kenya. The study "Promoting Biogas Systems in Kenya" dated 18 October 2007 was carried out by ETC UK, in collaboration with ETC East Africa, ETC Energy, and local consultants Integral Advisory Ltd (KBFS, 2007). While recognising the potential to install an estimated 65,000 biogas plants in Kenya in just over 10 years, the Kenya Biogas Feasibility Study (KBFS) characterised the current market for biogas in Kenya as immature, with slow NGO and private sector-led sales, driven by a small number of pioneers. It was noted that the stakeholders have limited capacity to generate the level of activity that would spur absorption of the inherent but untapped demand. The market leader for household plants was estimated to install only about 
30 systems a year, with total market activity at around 100 systems per annum and cumulative installations of about 2,000 (KBFS, 2007; DGIS, Hivos and SNV, 2008).

Despite this potent demand, development of a vibrant biogas market has been elusive. The operational status of existing biogas plants is believed to be average to poor, even though data on the same is incomplete. Research shows that $30 \%$ of biogas systems may not be in working condition, the notable causes being poor design and construction, low end-user awareness on system management, lack of standards to govern the sector, poor water supplies and poor development of the dairy industry. National and international organizations (both Government and NGO), as well as the private sector, have promoted, trained technicians, and given technical support to the biogas industry over the last 50 years though in a fragmented approach. Most biogas plants installed currently are on cash basis, even though some are supported by grants and/or financing by donors (SNV, 2009).

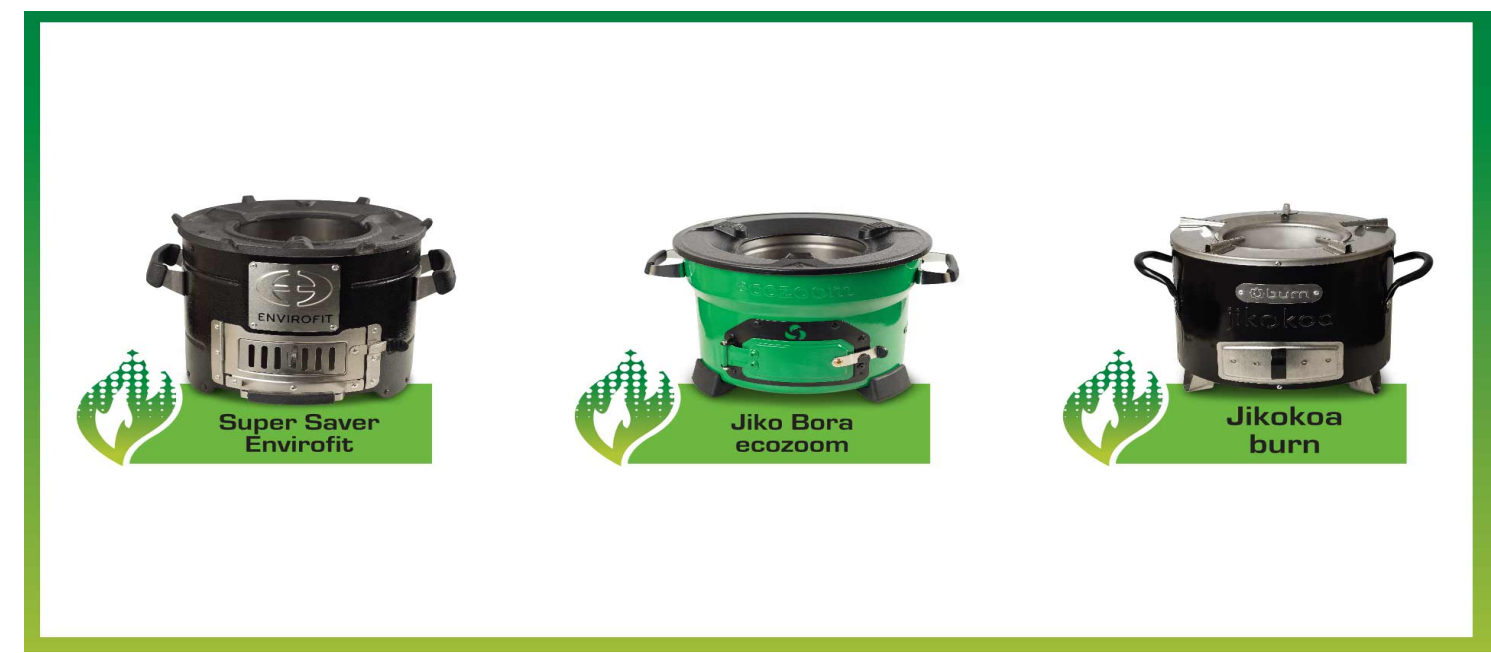

IMAGE 7: The figures below show other cookstoves that have been promoted in Kenya

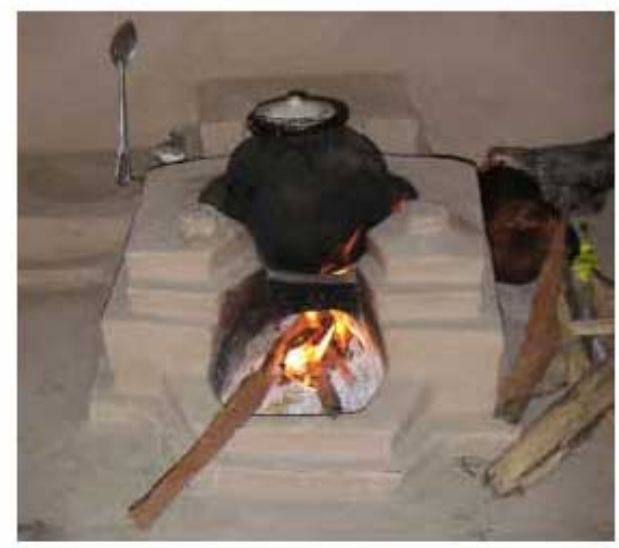

Single pot Jiko Kisasa with a traditional pot

IMAGE 8: Jiko Kisasa Single Pot

\section{RESEARCH METHODOLOGY}

The study used ex post facto research design because it was appropriate for investigating possible cause-and-effect relationships by observing an existing condition or state of affairs and searching back in time for plausible causal factors. In addition, it allowed the researcher to explore the answers to questions such as what factors seem to be associated with certain occurrences, or conditions, or aspects of behavior (Cohen et al., 2007). Mixed method research was used as it allowed collection and analysis of both qualitative (open-ended) and 
quantitative (closed-ended) data in response to research questions since the two forms of data were integrated in the study (Creswell, 2014). Mixed method research was used in order to draw on the strengths of both qualitative and quantitative methods together in one study. The core assumption of this form of inquiry was that the combination of qualitative and quantitative approaches provided a more complete understanding of the research problem than either approach alone (Creswell, 2013).

\section{Cooktoves for Household Cooking}

\section{RESULTS AND DISCUSSION}

The study identified various cookstoves owned and used by households as illustrated in figures 1 and 2. There are more three stone fire stoves in Rangwe (49\%) than in Suba North (27\%). This could be attributed to the availability of easily accessible firewood in Rangwe. The number of households using Kenya ceramic jiko was high in Suba North (156) compared to Rangwe (108). The same trend was observed for charcoal all metal stove (which is classified as a traditional stove).

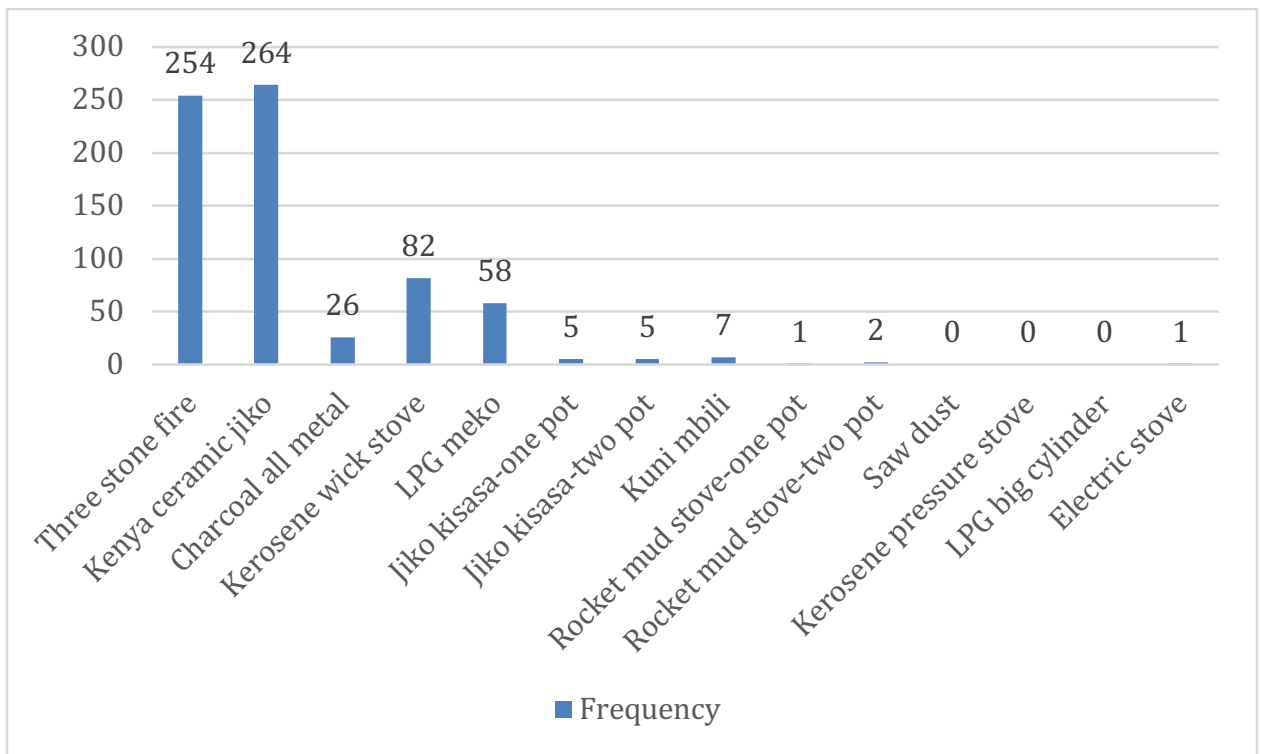

Figure1: Cookstoves for Household Cooking in Homa Bay County

National Institute of Population Research and Training (2009) also found that across rural Bangladesh, $98 \%$ of the population continues to cook with biomass in traditional cookstoves despite years of efforts to promote nontraditional cookstove technologies. According to ESMAP (2010) traditional cookstoves are inefficient, harnessing only 5-15\% of biomass energy. The evidence of significant use of traditional cookstoves therefore raises important questions about health and environmental risks associated with burning biomass in traditional cookstoves

The number of households having ICS such as firewood jiko kisasa-one pot and two pots, rocket mud stove-one pot and two pot, sawdust stove, kerosene pressure stove and electric stove remained low in both constituencies. This is in line with the statement of WHO (2002) and Health Effect Institute that despite the negative effects of traditional cookstoves, half of the world's population and $75 \%$ of South Asians continue to burn solid fuels in inefficient traditional cookstoves for cooking and heating. Smith and Heigler (2008) also allude that many governments and development organizations have attempted to combat indoor air pollution by disseminating cleaner-burning cookstoves, but the adoption and use of these nontraditional cookstoves in the developing world has, with few exceptions, remained disappointingly low. This has been confirmed in the study area. 


\section{Fuels for Household Cooking}

Figure 2 shows that household cooking fuels came from four main sources. These included biomass, charcoal, kerosene and LPG. Use of firewood was reported in both sub-counties but use of biomass as fuel is dominant in Rangwe as opposed to Suba North where the dominant fuel is charcoal.

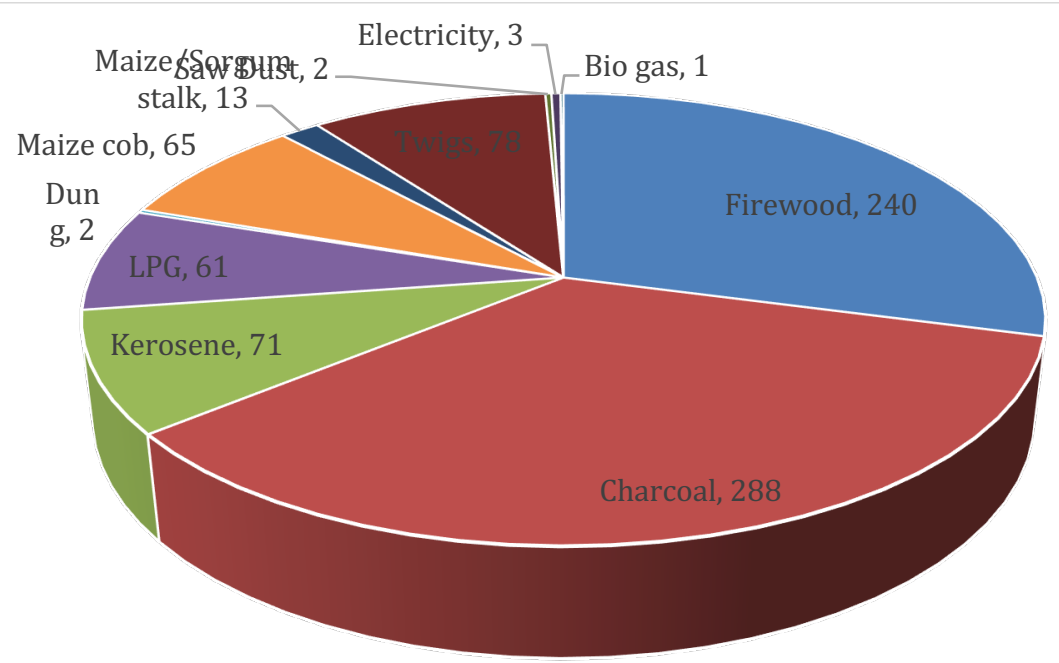

Figure 2: Fuels for Household Cooking in Homa Bay County

This agrees with the findings of the National Sample Survey $68^{\text {th }}$ round, that the dominant fuel mix in rural India still consists of firewood and chips, with around two thirds of the households still dependent on them. Fuel wood, crop residue and animal dung are the three important types of biomass used in Ghaziabad (Government of India, 2015). Similarly, in the Philippines, cooking and water heating account for $90 \%$ of household energy use, and fuelwood provides $75 \%$ of the total energy used in rural areas and more than $25 \%$ in urban areas (Dutta, 2003).

Though Suba North recorded high use of firewood, respondents explained that firewood was only used on special occasions. Suba North recorded very high use of charcoal and kerosene compared to Rangwe. Though kerosene is often advocated as a cleaner alternative to solid fuels, biomass and coal, for cooking some kerosene-using devices emit substantial amounts of fine particulates, carbon monoxide (CO), nitric oxides $\left(\mathrm{NO}_{\mathrm{x}}\right)$, and sulfur dioxide $\left(\mathrm{SO}_{2}\right)$ (Cooper et al., 2012). Studies of kerosene used for cooking or lighting provide some evidence that emissions may impair lung function and increase infectious illness (including tuberculosis), asthma, and cancer risks. There is a strong and consistent body of evidence indicating that exposure to fine particulate matter (PM) increases the risk of respiratory and cardiovascular disease, cancer, and mortality (Krewski et al., 2005; Samet and Krewski, 2007; Yang, 2008; Tsai et al., 2012). Households in Suba North explained that they had to switch to charcoal and kerosene because of scarcity and high cost of firewood. The study also revealed that electricity and biogas had not been widely adopted as cooking fuels.

\section{Fuel for Household Lighting}

Household lighting is a fundamental need, required in the home to extend work and study hours, and allow household tasks and social gatherings. Respondents were asked to state the type of lamps used for lighting. The data shows that shows that the number of households using kerosene was high in both constituencies. Two types of lamps were in use: kerosene tin lamp known as "nyangile" (Suba North (83) and Rangwe (84)) and kerosene Chinese lamp 
(Suba North (7) and Rangwe (40). Suba North reported high adoption of electricity (50) and solar lamp (108) compared to Rangwe : electricity (27) and solar lamp (28).

During FGD respondents from Rusinga explained that ICIPE rolled out a solar-Delight project whereby households were trained on the benefits of solar energy and then given a solar lamp free of charge. However, they complained that the solar lamps were controlled from a central point. They were switched on between $6 \mathrm{pm}$ and $6 \mathrm{am}$. They also did not have provision for powering radio, TV and for charging mobile phones. Suba North also reported the use of candles and battery flash light.

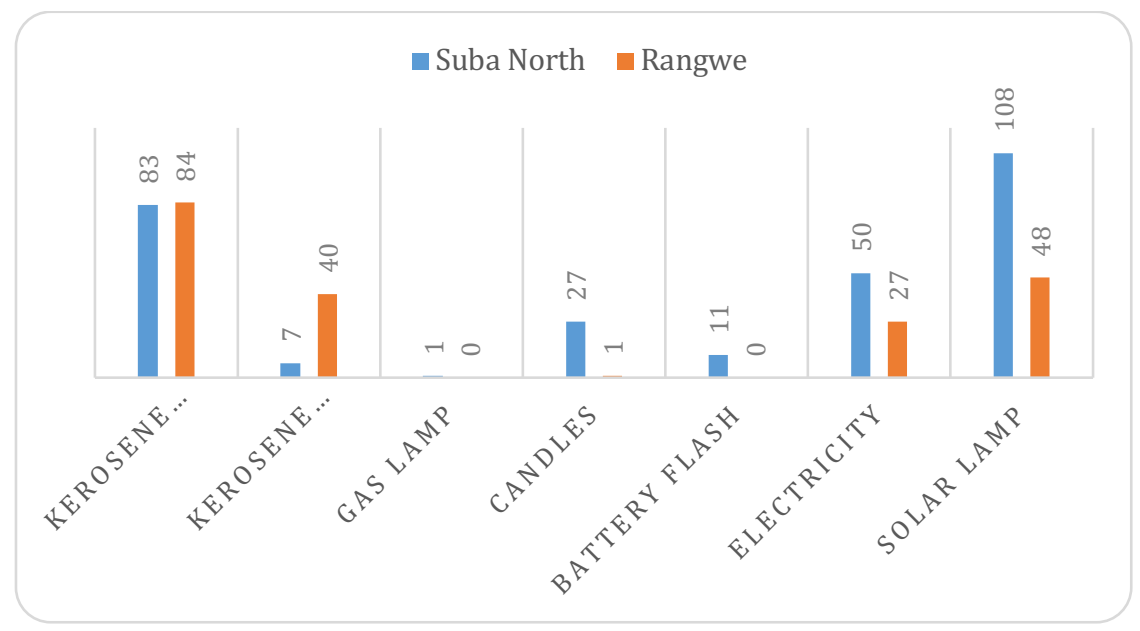

Figure 3: Fuels for Household Lighting

This supports the findings in Ghana that Households' lighting sources come from six main sources. These include grid electricity, small generators, rechargeable lamps, solar lamps and candles and traditional lamps/paraffin (Adusei, 2012). To meet the Total Energy Access minimum standard for lighting, a household must have at least 300 lumens (a measure of light energy radiated by a light source) of light for a minimum of four hours per day (Practical Action, 2012).

Respondents were asked whether the lighting could be used for four hours. The finding shows that very few households meet the lighting minimum standards prompting the question; is there energy poverty in Homabay County?

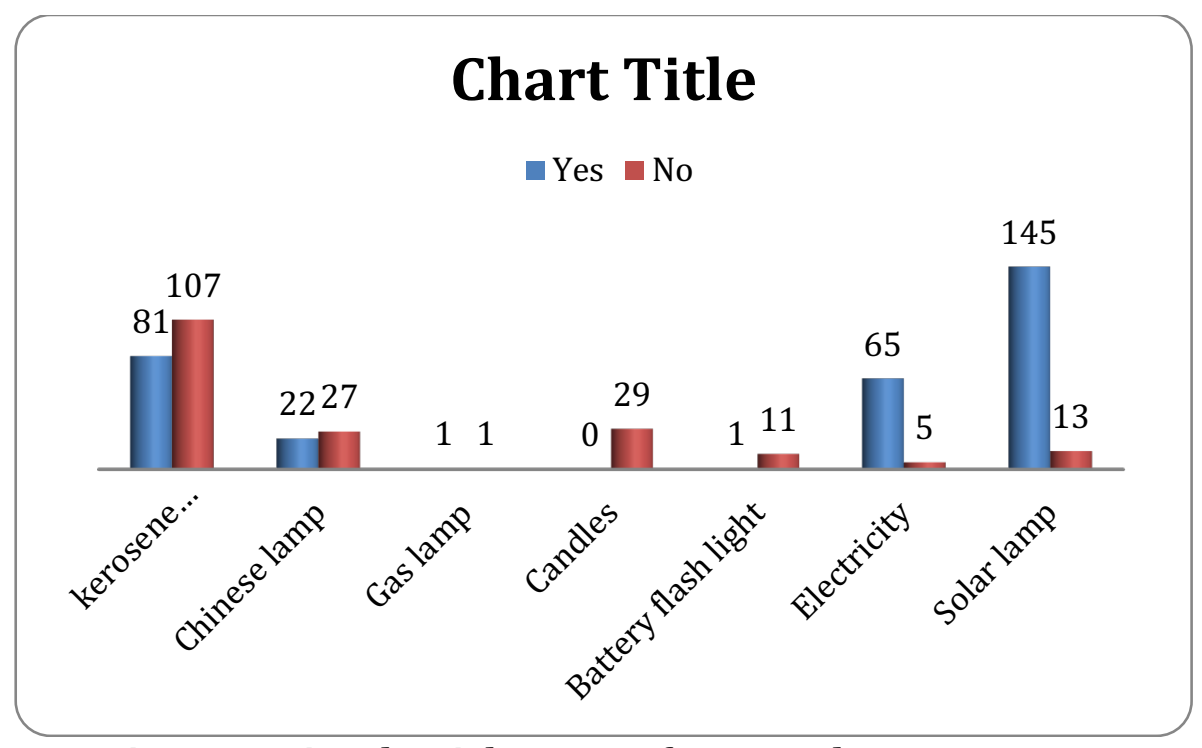

Figure 4 Using the Light Source for More than Four Hours 
Legros et al., (2009) found that nearly 1.5 billion people, around $22 \%$ of the global population, do not have access to electricity. This is significant because it means that those without electricity for lighting have to resort to lamps that are polluting, dangerous and provide lowquality light. These options are more expensive than modern electric light. The very poor use flaming brands, candles and kerosene wick lamps in contrast with the high-efficiency light bulbs accessible to those with electricity.

People without access to electricity use fuels for lighting that provide fewer luminescence or brightness (measured in lumens) for each watt of power consumed than electricity (Practical Action, 2012). A lumen ( $\mathrm{lm}$ ) is a measure of light energy radiated by a source. A kerosene wick lamp or a candle just provides $11 \mathrm{~lm}$ (PPEO, 2010) compared with $1300 \mathrm{~lm}$ from a 100w incandescent light bulb. This implies that those without access to electricity must endure light levels that are inefficient for safe work, study, or recreation.

Very few studies have been done on level of IAP from kerosene lamps. A preliminary study in Guatemala (Share and Smith, 1995) indicates an average particle emission of $540 \mathrm{mg} / \mathrm{hour}$ for wick lamps and $300 \mathrm{mg} /$ hour for enclosed lamps. This emission rate is relatively low compared to biomass stove emission (2.20g/hour), but the most polluting lamps emit levels that can compete with those from cleaner types of biomass stoves. However, recent studies (PoppenDieck, 2010) reveal that pollutants from the cheapest kerosene wick stoves have the smallest particle size, and are thus the most dangerous since they are taken more deeply into the lungs. Beside candles and wick lamps, if unguarded, are intrinsically unsafe and lead to injury and death, particularly among women and children.

Modern, efficient fuels produce a large amount of useful energy and little pollutants. However they are generally more expensive. Photovoltaic solar lamps (PSL) and ICS can benefit the welfare and health of households that cannot afford high-quality fuels. ICS are technologically designed to burn biomass fuel efficiently and under the right conditions so as to minimize the production of harmful byproducts in the combustion process. The new generation ICS bring down emissions up to 50\% (World Bank, 2012). PSL eliminate the need for kerosene fuels, since they rely on solar energy. This means PSL do not produce any damaging emissions.

\section{Knowledge about ICS}

Those who use traditional stove were asked to state the frequency of using three stone fire. This was to investigate whether poor information flow between producers, consumers and intermediary organistions could be complicating the shift to clean cooking. The results show that daily use of three stone fire was found to be very high in Gem West (38.2\%) followed by Gem East (25.8\%). Gembe had the highest number of households who used it often (62.5\%) and sometimes (42.1\%) while Rusinga had the highest number of those who use it for special occasions $(38.9 \%)$. 
Table 1 Frequency of Using Three Stone fire by Division

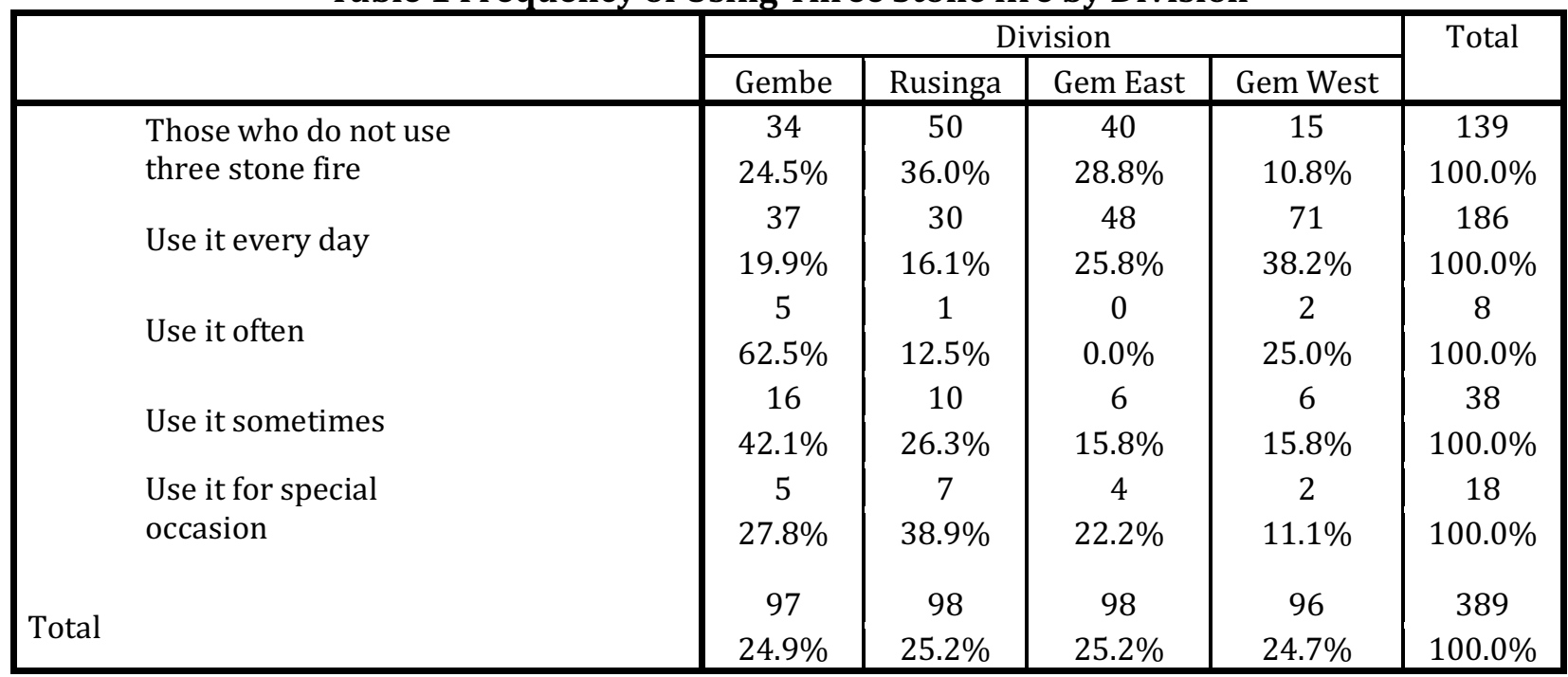

Those who had traditional stove only were asked if they had heard of ICS. The data shows that all the households from Rusinga had heard. A substantial number of households from Gem West had not heard.

Table 2 Knowledge of ICS among Those Who Did Not Have ICS

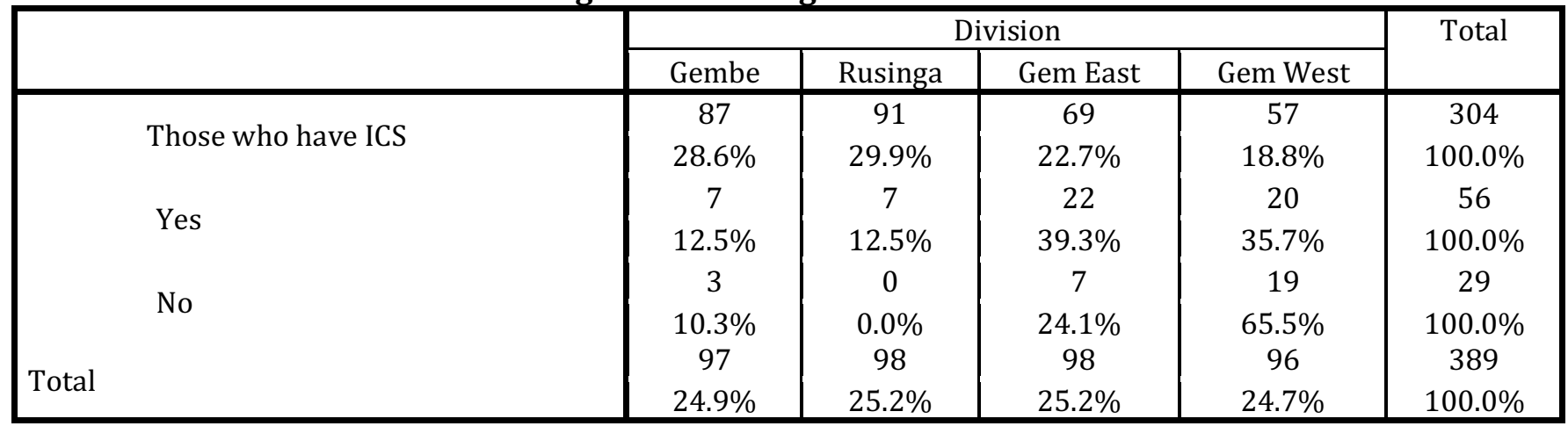

This agrees with a the findings of a study by IISD, (2013) that women in many rural communities lack information and capacity about clean, efficient, cooking technologies that could facilitate changing cooking habits. Those who had heard about ICS were asked to give reasons why they were not using ICS. The data shows that only households from Gem West $(100.0 \%)$ said that they did not know where to find it. Households from Gembe (33.3\%) and Gem West (66.7\%) did not have any knowledge about the dangers of indoor smoke while one household from Gem West complained that ICS were not accessible (100.0\%). The number of households who could not afford an ICS was distributed across the divisions. A further 50.0\% from Gem East, 30.0\% from Rusinga and 20.0\% from Gembe said that traditional stove better suited their use. 
Table 3 Reasons why Some Households were Using Traditional Stoves Only

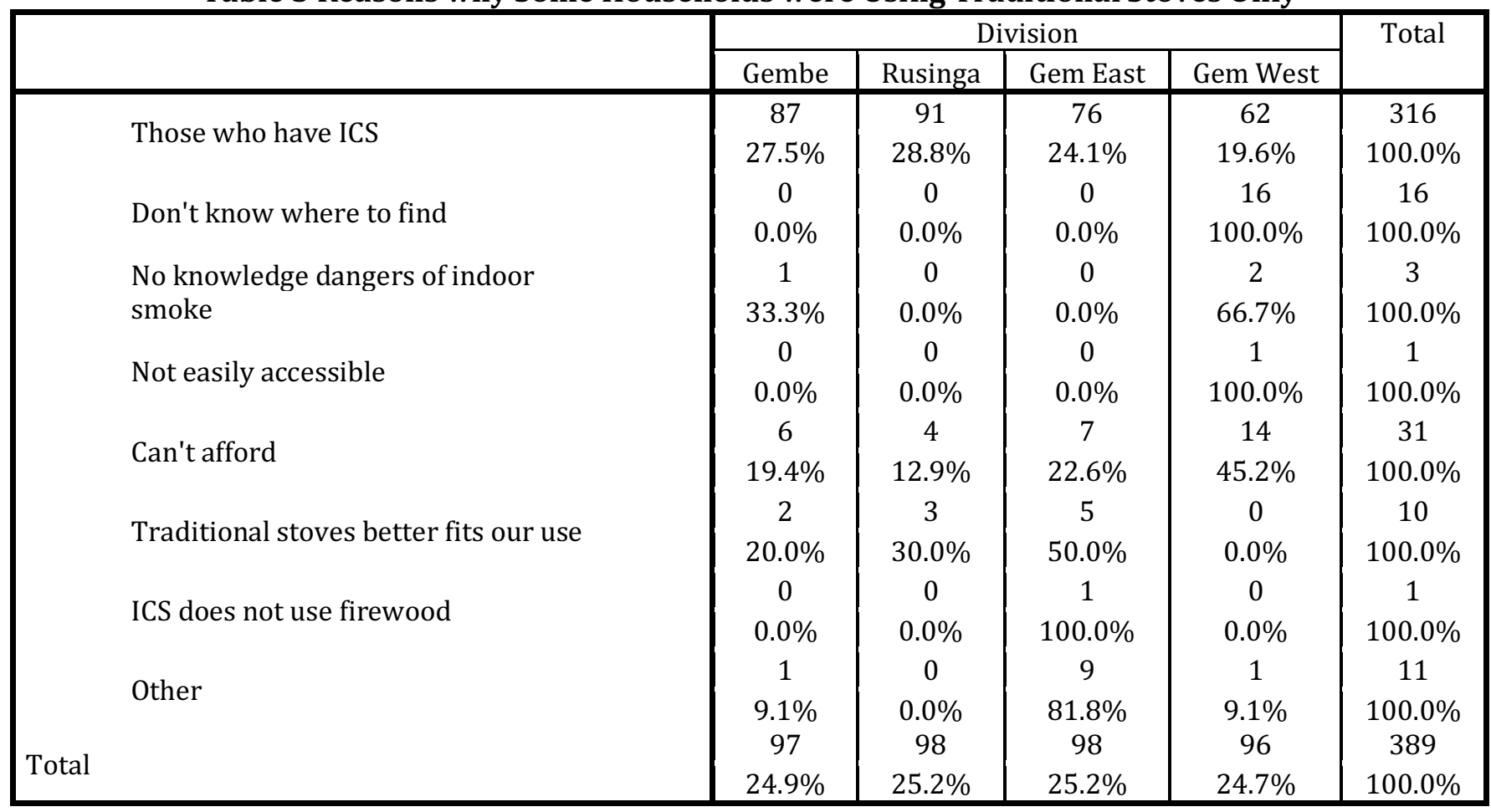

Households who were using traditional stove only were also asked to state if they were happy with the existing stove. The findings shows that 39.0\% of households from Gem West and $37.3 \%$ from Gem East said they were happy with the existing stove. All the households in Rusinga (7) were happy with the existing stove and $61.5 \%$ of households from Gem West, $26.9 \%$ from Gem East and 11.5\% from Gembe wished to switch to another type of stove.

Table 4 Whether Household Having Traditional Stove Were Happy With the Existing Stove or Wished to Switch

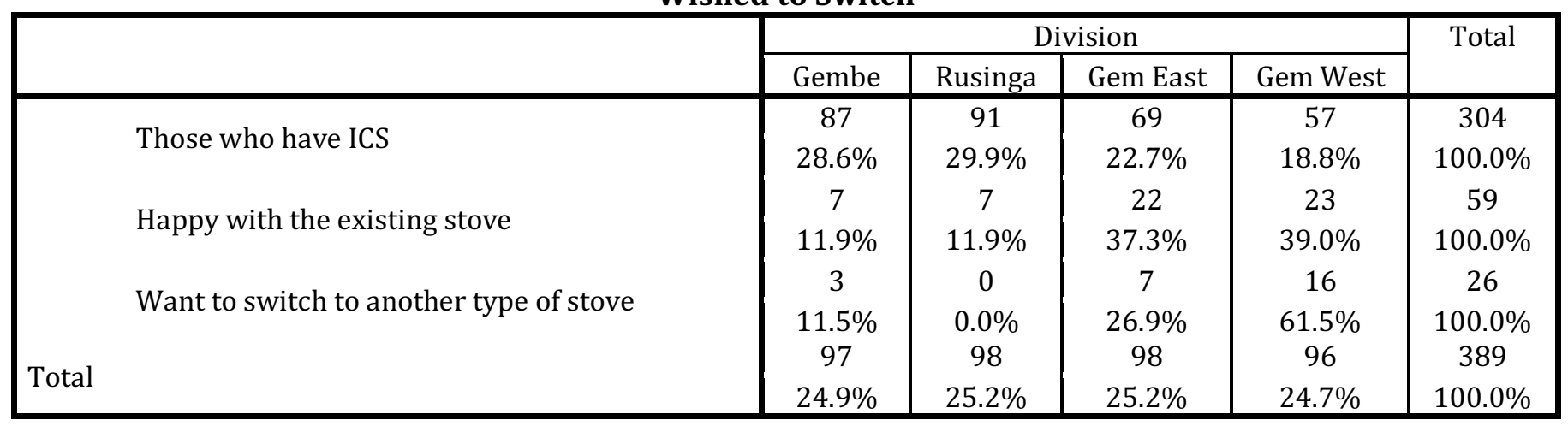

\section{Sources of Information about ICS}

Respondents who had ICS were asked to state how they came to know about the ICS for the first time. This was to determine whether they had access to information about the available alternatives and therefore a clear understanding of what their purchasing options are. The study findings show that radio (88) and neighbours/friends (175) have played an important role in creating awareness in both Suba North and Rangwe. So far, the role of the private sector (cookstove producers (13), marketing groups (79), NGOs (39)) seems to still be very low. In addition the role of public meetings/field days (9) and brochures/leaflets/calendars (9) was also very low. 


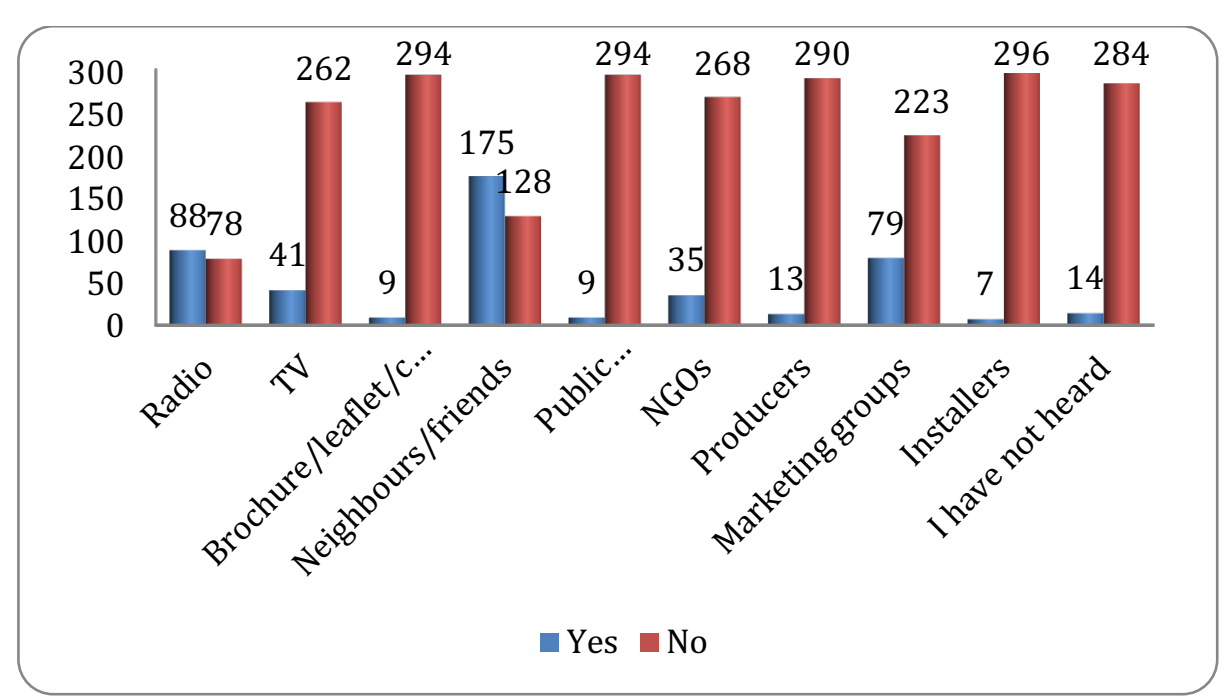

Figure 5 Sources of Information about ICS

Because many people have received little education that would help inform their choice of fuel, encouraging a shift to clean alternatives is a difficult task. However, it is likely that better awareness would increase consumers' willingness to make the change. Thus, public education would play an important role in encouraging a transition to clean cooking fuels. Respondents were asked to state whether they had been trained on kitchen and fuel management. The data shows that only 79 had received training. Gem East (31.6\%) and Gem West (38.0\%) had the highest number of those who had received training yet they reported low adoption of ICS. The number of respondents who had not received any training on kitchen and fuel management was high in all divisions.

Table 6 Training on Kitchen and Energy Management by Division

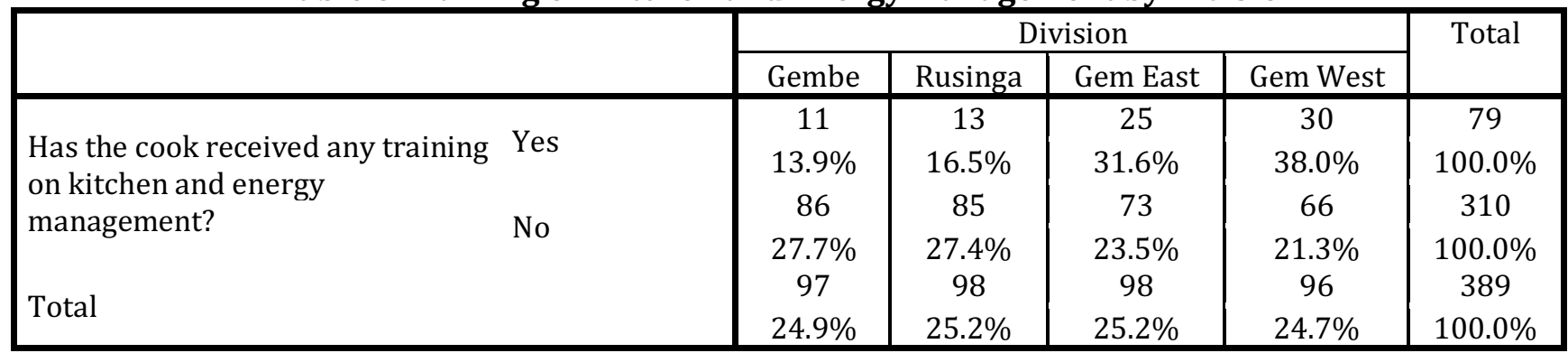

\section{CONCLUSION AND RECOMMENDATION}

The household energy pattern has remained dominated by the use of biomass in its traditional form. Regardless of the existence of various energy sources, the mixing of biomass with other transitional and clean fuels was found to be high. Therefore, there is a need to strengthen efforts to promote use of ICS, which use biomass in a more efficient ways. The limited use of improved cook stoves suggests a need to explore reasons for the low adoption rate, and a need to solve some technical problems experienced by adopters. Those promoting ICS, and technicians, should work with communities to address the socio-cultural and technical problems that lead to stove and fuel stacking, in order to increase the likelihood of adoption of ICS and clean fuels. 


\section{Reference}

Africa Biogas Partnership Programme Proposal to DGIS, August 2008

Arnold, J. E. M., Köhlin, R. Persson, and G. Shepherd. (2003). Fuelwood

Revisited: What Has Changed in the Last Decade? Center for International Forestry Research (CIFOR), Bogor, Indonesia

Clancy, J. and Skutsch, M. (2003). The Gender Energy Poverty News, Finding the Energy to Address Gender Concerns in Development. DFID Project. New York.

Coelho S.T. Karakezi S and Lata k (2004) . Traditional biomass; improving its use and moving to Modern energy use. Secretariat of the international conference for renewable energies Bonn( 2004 )Page 21-22.

Cohen, I., Manion, L., and Morrison, K. (2007). Research Methods in Education (6 ${ }^{\text {th }}$ Ed). Routledge: New York Creswell, J. W. (2014). Research Design: Qualitative, Quantitative, and Mixed MethodsApproaches. (4th ed). Sage Publications Limited: Los Angeles.

Dalberg analysis (2013). LPG Global prices are from 2011 LPG Association Report (calculated as avg. of butane and propane prices for Saudi Oil) and Purvin and Gertz; Kenya LPG and charcoal prices from 2005 to 2013 Q1 obtained from Timetric, data as of Apr. 2013. Fuel use databases collected by DHS, WB, maintained by WHO

Dutta, S. (2003) Mainstreaming Gender in Energy Planning and Policies. UNESCAP Project on Capacity Building on Integration of Energy and Rural Development Planning. United Nations New York.

ESMAP (2010). Improved Cookstoves and Better Health in Bangladesh: Lessons from Household Energy and Sanitation Programs. ESMAP Report. Washington, DC: World Bank

Government of India. (2015). Energy sources of Indian households for cooking and lighting,

IEA (International Energy Agency). (2006). World Energy Outlook. Paris: OECD

IEA (2011). “World Energy Outlook 2011: Energy for All - Financing Access for the Poor - Special Early Excerpt of the World Energy Outlook 2011

IEA (2012). World Energy Outlook 2012. Paris: OECD.

IISD (2013), "Post-2015 Development Agenda Bulletin. Summary of the High Level Meeting on Energy and the Post-2015 Development Agenda", 2013

Kammen, D. M., (1995). Cookstoves for the developing world, Scientific American, 273, 72 - 75.

Kammen, D. M., Bailis R., Herzog A. V. (2002). Clean Energy for Development and Economic Growth: Biomass and Other Renewable Energy Options to Meet Energy and Development Needs in Poor Nations, p. 12. New York: UN Dev. Programme/ Gov. Morocco

Karekezi, S. and Kithyoma, W., (2002). Renewable energy strategies for rural Africa: is PV led renewable energy strategy the right approach for providing modern energy to the rural poor of Sub-Saharan Africa? Energy Policy 30 (11-12) 1071-1086.Elsevier Science Limited, Oxford 126

Krewski D, Burnett R, Jerrett M, Pope CA, Rainham D, Calle E, Thurston G, Thun. M, (2005).

Mortality and long-term exposure to ambient air pollution: Ongoing analyses based on the American Cancer Society cohort. J Toxicol Environ Health A. 2005;68:1093-109. [PubMed]

KENGO, (1991). How to Make and Use the KCJ, KENGO/ Regional wood energy programme for Africa (RWEPA), Nairobi.

Kenya Biogas Feasibility Study (KBFS) “Promoting Biogas Systems in Kenya”, ETC UK, 18 October 2007

Legros G, Havet I, Bruce N, Bonjour S. (2009). The Energy Access Situation in Developing Countries: A Review Focusing on the Least Developed Countries and Sub-Saharan Africa. New York:United Nations Development Programme and World Health Organization

National Institute of Population Research and Training, Mitra and Associates, Macro International (2009)

Bangladesh Demographic and Health Survey 2007 (National Institute of Population Research and Training, Dhaka, Bangladesh).

Okello, V., (2005). The Upesi rural stoves project. Boiling point 51, 2005.

PPP Proposal for ABPP (DGIS, Hivos and SNV), August 2008. 
Donata, O. A., Leonard, M. S., \& Pacifica, M. (2019). Access to Modern Energy Initiatives by Rural Household in Homa Bay County, Kenya. Advances in Social Sciences Research Journal, 6(7) 266-280.

Petroleum Institute of East Africa (PIEA) (2011).

https://www.standardmedia.co.ke/business/article/2000216924/lpg-use-increases-by-83pc-says-report https://www.the-star.co.ke/news/2016/03/14/piea-backs-erc-on-fuel-prices_c1310942

Poppendieck, D., Apple, J., Vicente, R., Yarberry, A., Lohse, N., Tracy, J. (2010) Exposure to particulate matter from kerosene lamps. Report for the Second Global Business Conference and Trade Fair for Off-Grid Lighting in Africa, May 18-20, Nairobi, Kenya. Available at: http://lightingafricaconference.org/fileadmin/user upload/Conference_2010/Day2/DAY2_PDF/Dustin Poppend ieck-Lighting Africa 2010 - Poppendieck.pdf

Practical Action (2010) Poor people's energy outlook 2010, Rugby, UK.

Practical Action (2012): Poor People's Energy Outlook 2012 - Energy for Earning a Living. Retrieved from: http://practicalaction.org/ppeo2012

Ramanathan, V., and G. Carmichael. (2008). "Global and Regional Climate Changes Due to Black Carbon." Nature Geoscience (March 23).

Samet J, Krewski D (2007). Health effects associated with exposure to ambient air pollution. J Toxicol Environ Health A. 2007;70:227-42. [PubMed]

Schare S, and Smith KR (1995). Particulate emission rates of simple kerosene lamps. Energy Sustain Dev. 1995;2:32-35

Smith, K.R. (1993) "Fuel Combustion, Air Pollution Exposure, and Health: The Situation in Developing Countries", Annual Reviews Energy and Environment 18: 529-566.

Smith KR, and Haigler E (2008) Co-benefits of climate mitigation and health protection in energy systems: Scoping methods. Annu Rev Public Health 29:11-25.

SNV, (2009). Kenya National Domestic Biogas Programme: An initiative under the Africa Biogas Partnership Programme

Tsai SS, Chen PS, Yang YH, Liou SH, Wu TN, Sung FC, Yang CY. Air pollution and hospital admissions for myocardial infarction: Are there potentially sensitive groups? J Toxicol Environ Health A. 2012;75:242-51. [PubMe

UNDESA (2010), The World's Women 2010

UNDP (2011). Human Development Report, "Sustainability and Equity: A Better Future for All," 2011;

UNDP, and WHO (World Health Organization). (2009). The Energy Access Situation in Developing Countries: A Review Focusing on the Least Developed Countries and Sub-Saharan Africa. New York: UNDP and WHO.

Venkataraman, C, A. D. Sagar, G. Habib, N. Lam, and K.R. Smith. (2010). "The Indian national initiative for advanced biomass cookstoves: the benefits of clean combustion." Energy for Sustainable Development 14 (2):6372 .

WHO (2002) World Health Report 2002: Reducing Risks, Promoting Healthy Life (World Health Organization, Geneva).

WHO (2011). Inter-Governmental Panel on Climate Change, Working Group II “Chapter 9: Africa,” 2007; World Health Organization (2011)

World Bank (2012) World Development Report. Washington DC: World Bank.

World Bank (2012) http://data.worldbank.org/country/kenya, accessed on: 10 June 2012.

Yang C. Y. (2008). Air pollution and hospital admissions for congestive heart failure in a tropical city: Taipei,

Taiwan. J Toxicol Environ Health A. 2008;71:1085-90.[릴ed] 